\title{
PERFIL DE TEXTURA E UMIDADE ESPREMÍVEL DE GÉIS DO ALBUME DE OVOS RECOBERTOS COM SORO DE LEITE ${ }^{1}$
}

\author{
Ana Cláudia Carraro ALLEONI ${ }^{2, *}$, Aloísio José ANTUNES ${ }^{3}$
}

\begin{abstract}
RESUMO
A gelatinização é uma importante propriedade funcional das proteínas alimentares, devido ao seu grande potencial de uso nos alimentos estruturados. As proteínas da clara do ovo de galinha têm sido extensivamente usadas como ingredientes em alimentos processados. O objetivo deste trabalho foi avaliar as mudanças no $\mathrm{pH}$, no perfil de textura e na umidade espremível de géis de clara de ovos de galinha com e sem cobertura de concentrado protéico de soro de leite, armazenados a $25^{\circ} \mathrm{C}$, por $3,7,10,14,21$ e 28 dias. A dureza do gel do albume de ovos sem cobertura foi maior do que a de ovos recobertos, durante todos os periodos de armazenamento. Não houve efeito do tempo de armazenamento na dureza dos géis dos ovos sem cobertura. Em ovos cobertos, a regressão linear explicou $60 \%$ do comportamento da dureza em relação ao período de armazenamento. No caso da elasticidade, não houve interação entre periodo de armazenamento e a cobertura. Houve diferença entre as médias dentro de cada período, mas não durante o armazenamento. A maior elasticidade foi dos géis de ovos sem cobertura, comparados com os géis de ovos recobertos. O índice de coesividade e a mastigabilidade de géis de ovos sem cobertura foi maior que o de géis de ovos recobertos, em todos os períodos de armazenamento. A percentagem de umidade espremivel (UE) de géis de clara de ovos recobertos foi maior do que a de ovos sem cobertura em todo o periodo de estocagem.
\end{abstract}

Palavras-chave: clara de ovo; gel; dureza; elasticidade; coesividade; umidade espremivel.

\section{SUMMARY}

TEXTURE PROFILE AND EXPRESSIBLE MOISTURE IN ALBUME GELS OF EGGS COATED WITH WHEY. Gelation is an important functional property of alimentary proteins, and egg white proteins are extensively used as processed food. The objective of this work was to evaluate changes in the $\mathrm{pH}$, in the texture profile and in the expressible moisture of fresh egg white gels and eggs coated or not by whey protein concentrate, under $3,7,10,14,21$ and 28 days, at $25^{\circ} \mathrm{C}$. Hardness of the albumen gel of non-coated eggs was higher than the coated eggs, during the whole storage period. For the non-coated eggs, the storage period did not affect the hardness of the gels, but for the coated eggs, a linear regression explained $60 \%$ of the behavior of the hardness as a function of the storage period. When considering the gel elasticity, no interaction was found between the storage period and the egg coating. Non-coated eggs exhibited gels with higher springiness than coated eggs. The same was found for the cohesiveness index and the gel chewiness, independently of the storage periods. The percentage of expressible moisture for coated eggs was higher than for non-coated eggs.

Keywords: egg white; gel; hardness; springiness; cohesiveness; expressible moisture.

\section{1 - INTRODUÇÃO}

A qualidade interna do ovo altera-se imediatamente após a postura, devido a fatores como perda de água (perda de peso) e $\mathrm{CO}_{2}$ através da casca, liquefação do albume, movimentação de líquidos entre os compartimentos, distensão e flacidez da membrana vitelina da gema, que pode vir a romper [19]. Essas mudanças alteram algumas propriedades funcionais, como a gelatinização. Uma das primeiras mudanças é o aumento do $\mathrm{pH}$ da clara, cuja faixa de variação em ovos frescos é de 7,6 a 8,5, podendo atingir o máximo de 9,7 em ovos armazenados $[14,15]$. O aumento do $\mathrm{pH}$ do albume é causado pela perda de $\mathrm{CO}_{2}$ através dos poros da casca. $\mathrm{O} \mathrm{pH}$ do albume é dependente do equilíbrio entre dióxido de carbono dissolvido, íons de bicarbonato, íons

1. Recebido para publicação em 06/02/2004. Aceito para publicação em 05/12/2004 (001284). Parte do trabalho de tese de doutorado da primeira autora para obtenção do titulo de Doutor em Alimentos e Nutrição, na Faculdade de Engenharia Alimentos (FEA), da Universidade Estadual de Campinas (Unicamp).

2. Universidade Norte do Paraná, UNOPAR, Londrina, PR. End.: R. Athaualpa Vaz de Mello, 179 - CEP:13405-120, Piracicaba, SP. E-mail: anaccarraro@terra.com.br

3. Departamento de Nutrição e Planejamento Alimentar, Faculdade de Engenharia de Alimentos, UNICAMP.

* A quem a correspondência deve ser enviada. de carbonato e proteína. As concentrações de íons bicarbonato e carbonato são governadas pela pressão parcial do dióxido de carbono $\left(\mathrm{CO}_{2}\right)$ no ambiente externo [14].

A clara do ovo contém, aproximadamente, cerca de 9,7 a $12 \%$ de proteína $[15,20]$ e pode ser considerada um sistema constituído de numerosas proteínas globulares numa solução aquosa. A ovalbumina, conalbumina, ovomucóide, ovomucina e lisozima respondem por quase a totalidade das proteínas presentes na clara do ovo (p/p) [22]. A ovalbumina e a conalbumina representam, quantitativamente, cerca de $70 \%$ do total de proteínas da clara de ovo, e estão altamente relacionadas com as propriedades de gelatinização do albume. Estas proteínas podem ser gelatinizadas individualmente com tratamento alcali, enquanto as outras proteínas da clara do ovo não possuem esta característica [6]. As proteínas da clara e da gema possuem habilidade de se coagularem e funcionarem como uma espécie de ligação entre outros ingredientes [20]. As proteínas formam géis por meio da polimerização ordenada das moléculas, resultando uma rede tri-dimensional, sendo que esse processo ocorre por meio da transformação do líquido viscoso em uma matriz viscoelástica [11].

Durante o armazenamento, podem ocorrer algumas mudanças nas características físicas, microbiológicas, 
químicas e funcionais dos ovos. Essas mudanças dependem das condições de armazenamento [15, 18]. ALLEONI \& ANTUNES [1] trabalharam com ovos armazenados a $25^{\circ} \mathrm{C}$, com $75 \%$ de umidade relativa, e observaram diminuição na qualidade interna dos ovos após sete dias de armazenamento. Neste mesmo período e temperatura de armazenamento, ovos recobertos com concentrado protéico de soro de leite apresentaram melhor qualidade [2] e maior estabilidade da espuma do albume [3] comparados aos ovos sem cobertura.

A utilização de filmes protéicos para conservação de alimentos vem sendo empregada há muito tempo [7]. Os filmes e as coberturas comestiveis promovem a diminuição da perda de umidade e do transporte de gases $\left(\mathrm{O}_{2}\right.$ e $\left.\mathrm{CO}_{2}\right)$, o retardamento da volatilização de componentes aromáticos, além de funcionarem como veículo de aditivos [13].

Considerando-se que novas alternativas para armazenamento são essenciais para prolongar a vida-deprateleira de ovos e podendo entretanto, alterar as propriedades funcionais das proteínas da clara, principalmente a propriedade de gelatinização e de espessamento em sistemas de alimentos, torna-se importante a avaliação da aplicação de coberturas protéicas na casca de ovos, com vistas à preservação da qualidade desse produto para o consumo.

O objetivo deste trabalho foi avaliar as mudanças no $\mathrm{pH}$, no perfil de textura e na umidade espremível de géis de clara de ovos de galinha submetidos à aplicação de cobertura de concentrado protéico de soro de leite (CPSL), em função do armazenamento.

\section{2 - MATERIAL E MÉTODOS}

Foram utilizados ovos colhidos de galinhas ("Hyline" variedade W-36) logo após a postura, na Granja Bandeirantes S/A, localizada na cidade de Sumaré SP. Durante a condução do experimento foi controlada a dieta, a base de milho. Os ovos foram higienizados com solução de hipoclorito de sódio a 1\%. Em seguida, foram divididos em dois grupos: em um grupo foi aplicada uma cobertura à base de CPSL, e em outro grupo de ovos não foi aplicada cobertura. Para aplicação da cobertura, os ovos foram imersos na solução de CPSL por $1 \mathrm{~min}$, sendo depois secos a temperatura ambiente. A seguir, os ovos foram armazenados em grades de papelão, numa câmara BOD (Biological Oxigen Density) a $25^{\circ} \mathrm{C}$ e umidade relativa $80 \%$. Nos períodos $3,7,10$, 14,21 e 28 dias foram selecionados aleatoriamente 10 ovos de cada tratamento. Os ovos foram abertos, e as claras foram separadas das gemas através de um separador de claras.

\section{1 - Cobertura protéica}

A solução de cobertura foi preparada seguindo-se a metodologia de GENNADIOS et al. [8], com algumas modificações: $10,78 \mathrm{~g}$ de concentrado protéico de soro de leite (CPSL) (8\% de proteína), 3,5g de glicerol, completado para $100 \mathrm{~g}$ de água $(\mathrm{p} / \mathrm{p})$. A solução foi homogeneizada até a completa dissolução e submersa em água a $90^{\circ} \mathrm{C}$ por 30 minutos. Em seguida, foi resfriada até $25^{\circ} \mathrm{C}$, e o pH foi ajustado para 7,0 , com solução de $\mathrm{NaOH}$ $1,0 \mathrm{~N}$.

\section{2 - pH do albume}

$\mathrm{pH}$ do albume foi medido com o auxílio de um potenciômetro Micronal B374, anteriormente a homogeneização das claras.

\section{3 - Análise do perfil de textura}

A preparação das amostras seguiu o procedimento de MONTEJANO, HAMANN \& LANIER [17]. Claras de 10 ovos foram homogeneizadas por 5 minutos com agitador magnético na velocidade mínima, para prevenir a formação de bolhas de ar. Com o auxílio de uma pipeta volumétrica, $10 \mathrm{~mL}$ foram colocados em tubos de vidro vazados, de diâmetro interno $2,6 \mathrm{~cm}$, comprimento de $6 \mathrm{~cm}$ e tampa de borracha em cada extremidade. Finalmente, as extremidades foram lacradas com fita adesiva. Os tubos foram submersos verticalmente em água a temperatura de $90^{\circ} \mathrm{C}$ por 15 minutos, e em seguida foram resfriados numa cuba de gelo. Os géis foram removidos com o auxílio de uma agulha de seringa (a agulha foi introduzida entre o gel e a parede do tubo, fazendo o contorno do lado interno do vidro, para facilitar a remoção do gel). As amostras foram cortadas com estilete, formando cilindros com $1 \mathrm{~cm}$ de altura e submetidas à análise do perfil de textura (dureza, elasticidade, coesividade e mastigabilidade), com texturômetro TA - XT2, calibrado para uma força de compressão de 50\% em relação ao tamanho do gel, e uma velocidade do probe de $1,5 \mathrm{~mm} / \mathrm{seg}$.

\section{4 - Umidade Espremivel (UE)}

A determinação da umidade espremivel seguiu o procedimento de JAUREGUI, REGENSTEIN \& BAKER [12]. Amostras de 1 a 2 gramas do gel (cortadas em forma de cilindro) foram pesadas e colocadas em papel filtro Whatman n. 2, previamente pesado, juntamente com o tubo de centrifuga. As amostras foram centrifugadas a 2500 rpm por 10 minutos a $5^{\circ} \mathrm{C}$. Após a centrifugação, os géis foram removidos e pesaram-se, novamente, o papel mais o tubo. Para a obtenção da UE, utilizou-se a fórmula \%UE $=\{[($ Peso final do tubo + Papel $)-($ Peso inicial do Papel + Tubo)] x 100\} / Peso do Gel.

\section{5 - Análises estatísticas}

As determinações foram feitas com cinco repetições para método e triplicata para análise, e os períodos foram os dias de armazeamento. O delineamento experimental foi um fatorial $2 \times 6$, no qual os fatores foram cobertura e tempo. Foram realizadas comparações múltiplas das médias, envolvendo todos os tempos de armazenamento, inclusive o tempo zero (ovos frescos), aplicando a análise de um contraste ortogonal (tratamentos x ovos frescos). Comparações de médias foram feitas utilizando-se o teste de Tukey a 5\%.

\section{3 - RESULTADOS E DISCUSSÃO}

Houve interação entre os fatores cobertura e tempo de armazenamento para os atributos dureza, 
coesividade e umidade espremivel. Sendo assim, foi feito o desdobramento, e os resultados foram analisados dentro de cada período de armazenamento.

Em todos os períodos de armazenamento, a dureza do gel do albume de ovos sem cobertura foi maior do que a de ovos recobertos $(P<0,01)$. O pH da clara de ovos sem cobertura variou de 9,12 a 9,43, do terceiro ao vigésimo-oitavo dia, respectivamente, e o $\mathrm{pH}$ da clara de ovos recobertos variou de 8,01, no terceiro dia, a 8,33, no vigésimo oitavo dia (Tabela 1). CHANG \& CHEN [5] estudaram o efeito do $\mathrm{pH}$ nos géis de albume preparados a $100^{\circ} \mathrm{C}$ por 30 minutos e observaram aumento na força do gel após aumento do pH de 7,5 a 10. HANDA, TAKAHASHI \& FRONING [9] obtiveram o maior valor para a dureza de géis de albume no $\mathrm{pH} 11$, enquanto o menor valor foi no $\mathrm{pH} 3$ e no $\mathrm{pH} 7$. As ligações cruzadas intermoleculares das proteínas e as mudanças do grupo tiol para ligações dissulfidicas aumentam no $\mathrm{pH}$ mais alto, na faixa alcalina [9]. A formação das ligações dissulfidicas na clara do ovo contribui com a estrutura do gel formado e aumenta sua força [16].

Não houve efeito do tempo de armazenamento na dureza dos géis dos ovos sem cobertura. Em ovos recobertos, houve aumento linear na dureza com o tempo, sendo que a regressão linear explicou $60 \%$ do comportamento da dureza em relação ao período de armazenamento.

Com três dias de armazenamento a dureza de géis de clara de ovos sem cobertura foi $95 \%$ maior do que a de géis de clara de ovos recobertos (Tabela 1). Já com 21 dias de armazenamento, essa diferença caiu para $65 \%$, e com 28 dias foi de $58 \%$. Um dos fatores que influenciaram a dureza do gel do albume foi o $\mathrm{pH}$ da clara, que aumenta com o período de armazenamento. A CPSL retarda o aumento do $\mathrm{pH}$ durante o armazenamento, funcionando como uma barreira que impede a perda de $\mathrm{CO}_{2}$ pela casca. Ela mantém as características dos géis de ovos frescos, sendo que esse tipo de gel possui aparência não uniforme, como se possuísse bolhas de ar no seu interior. A aparência dos géis de albume de ovos frescos é frágil e granulada, com perda de água durante a compressão, a qual pode ser causada pela alta concentração de $\mathrm{CO}_{2}$ na clara de ovo fresca [10]. Com o aquecimento que ocorre durante o preparo do gel, bolhas de $\mathrm{CO}_{2}$ são criadas devido à diminuição de solubilidade, ocasionando a formação de um coágulo aerado [4].

Nos géis de clara de ovos recobertos, houve aumento de 27,6\% na dureza dos géis, entre 3 e 28 dias de armazenamento, passando de $512,6 \mathrm{~g}$ para $654,1 \mathrm{~g}$ (Tabela 1 ). $\mathrm{O}$ pH variou de 8,01, no terceiro dia, a 8,33, no vigésimo oitavo dia de armazenamento (Tabela 1), sendo que estes valores se encontram na faixa de $\mathrm{pH}$ de ovos frescos [15]. HAMMERSHØJ et al. [10] reportaram que os menores valores de pressão e a tensão de géis de albume foram obtidos em ovos frescos, como conseqüência do baixo $\mathrm{pH}$ e da alta concentração de $\mathrm{CO}_{2}$ na clara de ovo fresco. No pH na faixa de 7 a 8, ocorre repulsão eletrostática entre as moléculas de proteínas, sendo que nesta faixa as áreas de proteínas desnaturadas são limitadas a uma pequena região superficial da molécula; porém esta repulsão é menor do que a pH 9 [5]. No $\mathrm{pH}$ 6, a dureza de géis da clara de ovo foram as menores já obtidas por BEVERIDGE, ARNTFIELD \& CHUNG [4] e WOODWARD \& COTTERILL [21].

TABELA 1. Análise do perfil de textura e umidade espremível de géis da clara de ovos armazenados a 3, 7, 10, 14, 21 e 28 dias a temperatura de $25^{\circ} \mathrm{C}$.

\begin{tabular}{|c|c|c|c|c|c|c|c|}
\hline $\begin{array}{l}\text { Período } \\
\text { de } \\
\text { Armaze- } \\
\text { namento }\end{array}$ & $\mid \begin{array}{c}\text { Cober- } \\
\text { tura } \\
\text { (CPSL) }\end{array}$ & $\begin{array}{l}\mathrm{pH} \text { do } \\
\text { albume }\end{array}$ & $\begin{array}{c}\text { Dureza } \\
\text { (g) }\end{array}$ & $\begin{array}{c}\text { Elastici- } \\
\text { dade }\end{array}$ & $\begin{array}{c}\text { Coesivi- } \\
\text { dade }\end{array}$ & $\begin{array}{l}\text { Mastiga- } \\
\text { bilidade }\end{array}$ & \begin{tabular}{||c} 
Umidade \\
Espremível \\
$(\%)$
\end{tabular} \\
\hline Ovos & - & 7,93 & 492,0 & 0,85 & 0,69 & 288,6 & 50,06 \\
\hline frescos & & 0,16 & 24,6 & 0,05 & 0,01 & 11,2 & 0,06 \\
\hline \multirow[t]{4}{*}{3 dias } & Com & 8,01 & 512,6 & 0,91 & 0,62 & 293,7 & $52,65 \quad 0$ \\
\hline & Sem & 0,13 & 8,8 & 0,01 & 0,01 & 10,1 & 29,06 \\
\hline & & 9,09 & 997,6 & 0,94 & 0,73 & 690,1 & 0,01 \\
\hline & & 0,17 & 21,5 & 0,01 & 0,01 & 22,8 & \\
\hline \multirow[t]{4}{*}{7 dias } & Com & 8,03 & 571,8 & 0,89 & 0,64 & 317,3 & 51,07 \\
\hline & Sem & 0,10 & 40,9 & 0,01 & 0,01 & 12,3 & 0,27 \\
\hline & & 9,24 & 1058,1 & 0,94 & 0,74 & 735,4 & 31,45 \\
\hline & & 0,06 & 58,1 & 0,01 & 0,01 & 33,7 & 0,76 \\
\hline \multirow[t]{4}{*}{10 dias } & Com & 8,07 & 517,6 & 0,90 & 0,65 & 302,4 & 50,74 \\
\hline & Sem & 0,15 & 37,7 & 0,01 & 0,02 & 14,6 & 0,17 \\
\hline & & 9,35 & 997,0 & 0,95 & 0,73 & 686,1 & 31,81 \\
\hline & & 0,06 & 26,1 & 0,01 & 0,01 & 29,5 & 0,72 \\
\hline \multirow[t]{4}{*}{14 dias } & Com & 8,21 & 617,4 & 0,91 & 0,62 & 362,7 & $50,, 80$ \\
\hline & Sem & 0,10 & 44,9 & 0,01 & 0,02 & 12,8 & 0,59 \\
\hline & & 9,47 & 988,3 & 0,95 & 0,77 & 729,5 & 29,62 \\
\hline & & 0,10 & 46,5 & 0,01 & 0,01 & 28,7 & 0,80 \\
\hline 21 dias & Com & 8,23 & 636,2 & 0,91 & 0,65 & 338,2 & 50,20 \\
\hline
\end{tabular}

No caso da elasticidade, não houve interação entre o período de armazenamento e a cobertura. Porém, houve diferença entre as médias de dentro de cada periodo, mas não entre os períodos de armazenamento ( $T a-$ bela 1). Não houve efeito do tempo de armazenamento no índice da elasticidade do gel. A maior elasticidade foi dos géis de ovos sem cobertura (Tabela 1), comparados com os géis de ovos recobertos. O índice de elasticidade de géis de albume de ovos frescos foi 0,91; para géis de albume de ovos recobertos variou de 0,85 para 0,90 , enquanto para géis de albume de ovos sem cobertura variou de 0,93 para 0,94. O índice de elasticidade dos géis de ovos recobertos manteve o mesmo índice dos ovos frescos, de maneira análoga ao que ocorreu na dureza dos géis, em relação às características dos géis de ovos frescos.

O indice de coesividade de géis de ovos sem cobertura variou de 0,74 a 0,77. Já para géis de ovos recobertos 
o índice de coesividade variou de 0,64 a 0,69 (Tabela 1). A coesividade indica o quanto a estrutura do gel permaneceu intacta após a primeira compressão [9]. Sendo assim, a estrutura de géis de ovos sem cobertura alcançou uma coesividade maior do que a de géis de ovos recobertos. $\mathrm{O}$ indice de coesividade teve o mesmo comportamento do índice de elasticidade, ou seja, na faixa alcalina de $\mathrm{pH}$ a estrutura dos géis de ovos sem cobertura foi menos danificada do que a dos géis de ovos recobertos.

Comparando-se os resultados obtidos dentro do período de sete dias de armazenamento, os ovos recobertos apresentaram um índice de 0,64, enquanto nos géis de ovos sem cobertura eles foram iguais a 0,74 (Tabela 1). Com 28 dias de armazenamento, os índices de ovos recobertos foram 0,65 , e nos ovos sem cobertura, 0,78. Em todos os períodos de armazenamento, a diferença entre o índice de ovos recobertos e de ovos sem cobertura foi de $14 \%$, aproximadamente. Para BEVERIDGE, ARNTFIELD \& CHUNG [4], os indices de coesividade foram minimos no $\mathrm{pH} 6$ e foram maiores no $\mathrm{pH}$ 9. Os autores atribuíram este aumento ao aumento do $\mathrm{pH}$, ocasionando à mudança de grupo tiol para ligação dissulfídica, a qual é acelerada a pH 9.

$\mathrm{O}$ indice de mastigabilidade apresentou o mesmo comportamento da dureza dos géis (Tabela 1). A mastigabilidade dos géis de ovos sem cobertura foi maior do que a dos géis da clara de ovos recobertos, independentemente do período de armazenamento ( $\mathrm{Ta}$ bela 1). Neste caso, analisou-se apenas a cobertura, pois não ocorreu interação com o tempo de armazenamento. Géis formados a pH 11 exibem um valor extremamente alto de mastigabilidade [9]. Do terceiro ao vigésimo-oitavo dia de armazenamento, não houve diferença significativa para os géis de ovos recobertos. Já para os ovos sem cobertura o índice de mastigabilidade, a diferença foi significativa entre o terceiro e o vigésimo primeiro dia em diante.

A umidade espremivel (UE) de géis de clara de ovos frescos foi de $50 \%$. Com três dias de armazenamento, a UE para géis da clara de ovos recobertos foi de $53 \%$, e para géis da clara de ovos sem cobertura foi de $29 \%$ (Tabela 1). Portanto, a umidade espremivel dos géis de ovos sem cobertura foi $81 \%$ menor que a dos géis de clara de ovos recobertos. Para 7, 10, e 14 dias, essa diferença percentual caiu para 63\%. Com 21 dias, essa diferença voltou a subir para $78 \%$ e com 28 dias passou a $97 \%$. Géis da clara de ovos frescos são caracterizados pela sua pobre capacidade de retenção de água devido ao $\mathrm{pH}$ estar em torno de 7,5 a 8,0 [10]. Nesta faixa de $\mathrm{pH}$ ocorre repulsão eletrostática limitada entre as moléculas de proteínas, ocasionando uma perda maior de moléculas de água [5]. Por outro lado, em pH mais alto (em torno de 9), a maioria das proteínas estão carregadas negativamente; conseqüentemente, possuem repulsão eletrostática maior e têm maior capacidade de se ligar com a molécula de água [10].

Houve interação entre os fatores cobertura e tempo para a umidade espremivel (UE). Com isto, foi feita aná- lise de regressão, e os resultados foram analisados dentro de cada período de tempo. Para cada tempo de armazenamento houve diferença significativa $(P>0,01)$ entre os ovos com e sem cobertura (Tabela 1). Quanto maior a dureza, maior o índice de elasticidade, de coesidade, de mastigabilidade e menor a umidade espremivel dos géis, em $\mathrm{pH}$ alcalino.

\section{4 - CONCLUSÕES}

A cobertura de concentrado protéico de soro de leite (CPSL) mantém $\mathrm{pH}$ na faixa de ovos frescos. Durante todo o período de armazenamento, os atributos de dureza, elasticidade, coesividade, mastigabilidade e umidade espremivel em ovos recobertos foram inferiores aos dos ovos sem cobertura, mostrando uma influência não desejada para o processamento de alimentos. Por outro lado, este estudo nos mostra que podemos armazenar os ovos por período mais longos, antes de utilizá-los.

\section{5 - REFERÊNCIAS BIBLIOGRÁFICAS}

[1] ALlEONI, A.A.C.; ANTUNES, A.J. Unidade Haugh como medida da qualidade de ovos de galinha sob refrigeração. Scientia Agricola, v.58, n.4, p.681-685, 2001.

[2] ALLEONI, A.A.C.; ANTUNES, A.J. Internal quality of eggs coated with whey protein concentrate. Scientia Agricola, v.61, n.3, p.276-280, 2004.

[3] ALLEONI, A.A.C.; ANTUNES, A.J. Albumen foam stability and s-ovalbumin in eggs coated with whey protein concentrate. Revista Brasileira de Ciência Avicola, v.6, n.2, p.77-82. 2004.

[4] BEVERIDGE,T.; ARNTFIELD, S.; KO, S.; CHUNG, J.K.L. Firmness of heat induced albumen coagulum. Poultry Science, v.59, p.1229-1236,1980.

[5] CHANG, Y.I.; CHEN, T.C. Functional and gel characteristics of liquid whole egg as affected by $\mathrm{pH}$ alteration. Journal of Food Engineering, v.45, p. 237-241, 2000.

[6] CROGUENNEC, T.; NAU, F.; BRULÉ, G. Influence of $\mathrm{pH}$ and salts on egg white gelation. Journal of Food Science, v.67, n.2, p.608-614, 2002.

[7] DONHOWE, G.; FENNEMA, O. Edible films and coatings: characteristics, formation, definitions, and testing methods. In: KROCHTA, J.M.; BALDWIN, E.A.; NISPEROS-CARRIEDO, M.O. (Ed.) Edible coatings and films to improve food quality. Lancaster: Technomic Publishing, 1994. Cap.1, p.1-24.

[8] Gennadios, A.; BRANDENBURG, C. L.; WEller, C. L.; TESTIN, R. F. Effect of $\mathrm{pH}$ on properties of wheat gluten and soy protein isolate films. Journal of Agriculture and Food Chemistry, v.41, n.11, p.18351839, 1993.

[9] HANDA, A.; TAKAHASHI, N.K.; FRONING, G.W. Heatinduced egg white gels as affected by $\mathrm{pH}$. Journal of Food Science, v.63, n.3, p.403-407, 1998.

[10] HAMMERSHØJ, M.; LARSEN, L.B.; ANDERSEN, A.B.; QVIST, K.B. Storage of shell eggs influence the gelling properties. Lebensm. Wissens. und Technol., v.35, p.62-69, 2002.

[11] HERMAnssom, A.M. Agregation and denaturation involved in gel formation. In: SHERMAN, P. (Ed.) Food texture and rheology. New York: Academic Press, 1979. p.265. 
[12] JAUREGUI, C. A.; REGENSTEIN, J.M.; BAKER, R.R. A simple centrifugal method for measuring expressible moisture, a water-binding property of muscle foods. Journal of Food Science, v.46, p.1271-1273, 1981.

[13] KESTER, J.J.; FENNEMA, O.R. Edible films and coatings: a review. Food Tecnhology, v.40, n.12, p.4759, 1986.

[14] LI-CHAN, E.; POWRIE, W. D; NAKAI, S. The chemistry of eggs and egg products. In. W. J. STADELMAN; O. J. COTTERILL (Ed) Egg Science and Technology. Haworth Press, Inc.1994. Cap.6, p.105-176.

[15] MINE, Y. 1995. Recents advances in the understanding of egg white protein functionally. Trends in Food Sci. and Technol. v.6, n.7, p.225-232.

[16] MINE, Y. Effect of dry heat and mild alkaline treatment on functional properties of egg white proteins. Journal of Agriculture and Food Chemistry, v.45, p.29242928, 1997.

[17] MONTEJANO, J.G.; HAMANN, D.D.; LANIER, T.C. Thermally induced gelation of selected comminuted muscle systems-rheological changes during processing, final strengths and microstructure. Journal of Food Science, v.49, p.1496-1501, 1984.
[18] POWRIE, W. D. \& NAKAI, S. Chracateristics of edible and fluids of animal origin: egg. In. O. Fennema (Ed) Food Chemistry. Marcel Dekker, New York. 1985. Cap. 14, p.829-855.

[19] PROTAIS, J. Qualità dell'uovo da consume: caractterische ed alcuni fattori di variazione. Riv. Avicol., v.60, p.27-32.1991.

[20] VADEHRA, D. V. \& NATH, K. R. 1973. Eggs as a source of protein. Crit. Rev. Food Technol. 4(1): 193-308.

[21] WOODWARD, S.A.; COTTERILL, O.J. Texture and microstructure of cooked whole eggs yolks and heatformed gels of stirred egg yolk. Journal of Food Science, v.52, p.63-67, 1987.

[22] ZIEGLER, G. R. \& FOEGEDING, E. A. The gelation of proteins. In Advances in Food Nutrition Research. Kinsela, J. E. (Ed.). Academic Press, Inc. vol. 34. P.203-298. 1990.

\section{6 - AGRADECIMENTOS}

À Granja Bandeirantes Comércio de Ovos e Cítricos, localizada na cidade de Sumaré, SP, pela doação dos ovos. 
O arquivo disponível sofreu correções conforme ERRATA publicada no Volume 25 Número 2 da revista. 